\title{
PERIÓDICOS DE BOLSILLO. NOTAS SOBRE EL USO DE FORMATOS MENORES EN LA PRENSA LUSÓFONA DEL SIGLO XIX
}

\section{POCKET NEWSPAPERS. NOTES ON THE USE OF SMALL FORMATS IN THE LUSOPHONE PRESS OF 19TH CENTURY}

\author{
Maria Laura Romano ${ }^{1}$
}

\begin{abstract}
RESUMEN: El artículo analiza el uso de los formatos menores en dos periódicos del ámbito luso-brasileño decimonónico: O Correio Interceptado, de José Ferreira Borges (Londres, 18251826) y $O$ Mestre Barbeiro, de António José da Silva Monteiro (Porto Alegre, 1835). Propone una serie de hipótesis que correlacionan la elección del formato pequeño con una modalidad de lectura desplegada en contextos de fuerte censura o en condiciones erráticas de libertad de prensa. Asimismo, el texto indaga los sentidos ligados al tamaño de los periódicos construyendo un universo de impresos que incluye publicaciones periódicas y otra clase de objetos tipográficos.
\end{abstract}

PALABRAS CLAVE: prensa lusófona del siglo XIX; O Correio Interceptado; O Mestre Barbeiro; Formatos menores.

RESUMO: O artigo analisa o uso de formatos menores em dois jornais do século XIX do espaço luso-brasileiro: $O$ Correio Interceptado, de José Ferreira Borges (Londres, 1825-1826) e $O$ Mestre Barbeiro, de António José da Silva Monteiro (Porto Alegre, 1835). Propõe uma série de hipóteses que correlacionam a escolha do formato pequeno com uma modalidade de leitura implantada em contextos de forte censura ou em condições erráticas da liberdade de imprensa. Além do mais, o texto pesquisa os sentidos ligados ao tamanho dos jornais, construindo um universo de formas impressas que inclui jornais e outros tipos de objetos tipográficos.

PALAVRAS-CHAVE: Imprensa lusófona do século XIX; O Correio Interceptado; O Mestre Barbeiro; Formatos menores.

\footnotetext{
${ }^{1}$ Doutora (Instituto de Literatura Hispanoamericana da Universidad de Buenos Aires, Argentina), bolsista pósdoutoral do Conicet; https://orcid.org/0000-0002-1102-015X ; goriotlr@ hotmail.com 
Los pequeños libros todavía fascinan. [...]. La fascinación viene del hecho de que el libro tiene la fama de ser completo y de contener el mundo, lo que nos espanta aún más cuando su tamaño es reducido. El deslumbramiento también se justifica en virtud del respeto por la soledad del lector, siendo que el libro en pequeño formato comparte con él las emociones más secretas.

Michel Melot, Livro,

Dentro del conjunto de periódicos que encendieron los ánimos facciosos de la Porto Alegre de la década de 1830, se destacó una hoja anti-liberal titulada O Mestre Barbeiro, cuyos 32 números salieron a la luz entre enero y septiembre de 1835. Su redactor, António José da Silva Monteiro, murió en el primer enfrentamiento que dio lugar al largo conflicto conocido como Revolução Farroupilha ${ }^{2}$. Dos singularidades suelen destacarse de este papel: su sofisticado dispositivo de enunciación ${ }^{3}$ y su naturaleza satírica, forma a la que apeló casi de manera exclusiva en un contexto en el que aún no había germinado esa especie periodística. Al decir del historiador gaúcho Abeillard Barreto, se trató de "un periódico de formato mínimo que alcanzó el máximo de los desenfrenos folicularios” (Barreto, 1986, p. 14). Nos interesa la apreciación de Barreto no tanto porque informa acerca del estilo de la hoja, sino porque repara en uno de sus rasgos materiales: el historiador indica que se publicaba en un formato menor. En efecto, sus dimensiones no superaban el tamaño de lo que hoy llamamos "libros de bolsillo": apenas medía $11 \mathrm{~cm}$ de ancho por $16 \mathrm{~cm}$ de alto; más aún, colaboraba a su pequeñez el hecho de que estaba constituida tan solo por cuatro paginitas. He ahí una tercera singularidad. ¿Por qué, cuando la mayoría de los papeles públicos de la capital riograndense se publicaban en cuarto, salió a la luz una hoja en una medida tan pequeña?

Para un lector contemporáneo acostumbrado a la apariencia de la prensa actual, probablemente resulte llamativo que un periódico tuviese esas acotadísimas dimensiones. Sin embargo, se trataba de una característica que tenía variados antecedentes en el periodismo de la época. Existe poca bibliografía específica que haya abordado las propiedades materiales de la prensa. Más aún, son prácticamente inexistentes los estudios sobre el formato de los periódicos, asunto tratado en general en relación con el libro (Febvre y Martin, 2000 [1958]; Gaskell, 1999 [1972]; Petrucci, 1979; Chartier, 1994; Sánchez Vigil, 2018.). ${ }^{4}$ El historiador

\footnotetext{
${ }^{2}$ La Revolução Farroupilha se extendió por diez años (1835-1845), durante los cuales parte de la provincia de Rio Grande do Sul conformó una unidad política autónoma del Imperio brasileño, la República Riograndense. Analizado desde la historia de la formación del Estado nacional, este conflicto tuvo dos resortes desencadenantes. En primer lugar, la elite política heredera de la Independencia, que asumió el rol de trazar el armazón jurídicoadministrativo del Brasil pos-colonial, representaba los intereses del latifundio cafetero y azucarero, por lo que sus acciones tendían a velar por la inserción del país en el comercio internacional como exportador de materias primas. Esta orientación causaba constantes fricciones con los terratenientes de Rio Grande do Sul en la medida en que su producción (charque fundamentalmente) estaba destinada al mercado interno. Por otro lado, de manera confluyente con lo anterior, la inconformidad de los senhores da terra riograndenses se dirigía contra la centralización política y administrativa que las elites cariocas y paulistanas querían imponer sobre las provincias. Sobre este episodio de la historia brasileña puede consultarse: Pesavento, 1985; Flores, 1985; Kühn, 2002; Neves Alves, 2004.

${ }^{3}$ La redacción del periódico era atribuida a un barbero liberal; de ahí, su título. Este artilugio discursivo tenía por lo menos dos implicancias: en principio, convertía el papel en un caso extremo de la lógica de alusión del otro que caracteriza a la sátira. Asimismo, le permitía a su enunciador real -un defensor acérrimo de la monarquía absolutadesprestigiar el discurso del liberalismo haciendo decir a su marioneta periodística cataratas de inconsecuencias.

${ }^{4}$ El formato de los libros e impresos del período de la imprenta manual derivaba de la cantidad de dobleces hechos al pliego de papel. El tamaño octavo resultaba de doblar tres veces el pliego por el lado largo. Los pliegos de papel, debido a que se fabricaban artesanalmente, solían variar en sus dimensiones. En su Diccionario de bibliología y ciencias afines, José Martínez de Sousa anota que el octavo regular medía 11 x 16, precisamente el tamaño que presenta $O$ Mestre Barbeiro. Para la descripción material de los periódicos trabajados, usamos, además del diccionario mencionado, el libro de Philip Gaskell, Nueva introducción a la bibliografía material (1999).
} 
Jeremy Popkin, especialista en la prensa revolucionaria francesa, constituye una excepción. Sus trabajos no dejan de registrar los rasgos materiales de los impresos, a los que asocia con una particular cultura tipográfica en la que el dato tecnológico y material se liga con determinados usos políticos. Con respecto al tamaño de los periódicos, Popkin indica que los papeles parisinos de los tiempos de la Revolución se imprimían en octavo, dimensión que había sido previamente empleada para la publicación de panfletos. En la década de 1780, los impresores de París estaban familiarizados con ese formato y no requerían para emplearlo ningún equipamiento especial. Así, en momentos en que lo más importante era que las palabras salieran a la luz más allá de cualquier otra consideración, el formato en octavo era, según el historiador, "la elección natural para la primera tirada" de un emprendimiento periodístico (Popkin, 1989, p.154). Ahora bien, Popkin aclara que en la década siguiente, es decir 1790, ganó terreno el formato en cuarto. Paralelamente, el pequeño octavo, empleado en principio para toda clase de periódicos, comenzó a reservarse para las hojas de agitación política como Ami du peuple de Jean-Paul Marat y otras de ideología monárquica, que compartían con los papeles jacobinos el gusto por el estilo corrosivo y desmesurado.

Ciertamente no se puede establecer un vínculo inmediato entre $O$ Mestre Barbeiro y el periodismo de la Francia convulsionada tras la Revolución. No obstante, si se tienen en cuenta los trazos gruesos de la historia de la prensa a nivel global, pueden proponerse algunos entrelazamientos que permiten leer el papel brasileño dentro de una tradición vinculada al proceso de construcción de una esfera pública política, en cuyos albores se encuentra la prensa francesa revolucionaria. Es que, con su espíritu de partido, los papeles franceses posteriores a 1789 torsionaron la correlación entre el dispositivo periodístico y los ideales ilustrados (Popkin, 2004, p. 12). Si el objetivo de los primeros periódicos del siglo XVIII de universalizar la práctica del juicio crítico estaba basado en la creencia en la uniformidad ideológica de la comunidad de lectores a la que idealmente se dirigían, en los tumultuosos años de la posrevolución, la segmentación política de la prensa y de sus consumidores socavó ese ideal universalista. En Sudamérica, específicamente en el Imperio de Brasil, la conflictiva situación institucional en la que derivó la abdicación de D. Pedro I en 1831 tuvo su correlato en el crecimiento de los órganos de prensa (Stolze Lima, 2008, p. 57). Los periódicos de esta etapa, en la que el país estuvo gobernado por sucesivos regentes, poco honor hicieron a su ascendencia ilustrada tornándose un escenario privilegiado de las disputas políticas que dividían a la sociedad. $O$ Mestre Barbeiro fue uno de esas publicaciones de agitación que fundamentan que la prensa brasileña de aquellos años fuese calificada de "pasquineira" y "exaltada". ¿Habrá existido en su redactor, la voluntad de filiar la hoja con la zona más radical de la prensa parisina posterior a la revolución de 1789? Hay indicios de que Silva Monteiro estaba familiarizado con el pensamiento contrarrevolucionario de Francia, como testimonia la cita del conde de Montlosier ${ }^{5}$, de quien el redactor de Porto Alegre transcribió un discurso de fuerte contenido antiigualitario en el número 19 de su publicación. Por otra parte, entre las pocas líneas que restan sobre la vida del autor de $O$ Mestre Barbeiro, la necrológica nada halagüeña que le dedicó $O$ Recopilador Liberal constituye una valiosa fuente para reconstruir su perfil de escritor público: "Secretário y Agente do Coronel e Major da Legião, agitador de novidades, e Redactor [de] papeluxos que só servião para descompor, intrigar, insultar, e levar ao seio das familias as

\footnotetext{
${ }^{5}$ François-Dominique de Reynaud, conde de Montlosier, fue un político defensor de la monarquía que incursionó en la prensa de combate. Colaboró en el periódico Les Actes des Apôtres, distribuido en París entre 1789 y 1792. Fue la primera publicación de una serie periodística de signo contrarrevolucionario, como Sabbats Jacobites y Rocambole de Journaux, que empleó con generosidad desbordante la sátira para atacar a los adversarios políticos.
}

Rev. Bras. Lit. Comp. Niterói, v. 22, n. 39, pp. 121-132, jan. /abr. 2020. 
frases mais indecentes, e deshonestas" (308). ${ }^{6}$ El tono virulento del papel no permite desmentir esta caracterización. Si la apuesta de Silva Monteiro al incorporarse al mundo de la prensa fue devenir un "agitador de novidades", ¿qué mejor modelo que los periódicos de la Francia revolucionaria, "fenómeno único", según afirma Popkin, debido al público masivo que lograron conquistar y a su impacto genuino en los hechos políticos de la hora (Popkin, 2004, p. 15)?

Ahora bien, el análisis de los rasgos materiales de $O$ Mestre Barbeiro, en especial de su formato, puede adensarse más allá de la referencia al periodismo francés a través de la construcción de una trama de publicaciones periódicas en formatos menores al interior del universo de la prensa lusa del siglo XIX. En efecto, en los primeros años del período de las luchas liberales en la Península Ibérica, años en los que se produjo una explosión del número de periódicos en las principales capitales portuguesas (Tengarrinha, 1989, 123-134), se publicó una serie de hojas en octavo e incluso en dimensiones más pequeñas. Aunque no pueda decirse que esta cualidad material constituyera la marca de un tipo particular de publicación (correlación que, como demuestra Popkin, sí es válida para la prensa francesa de la época revolucionaria), no deja de resultar un antecedente interesante que permite ampliar la indagación, más aún cuando habilita a tejer relaciones entre publicaciones pertenecientes a un mismo ámbito lingüístico, cultural y político. Entre los papeles impresos en formato menor publicados en los años que siguieron a la Revolución liberal de $1820^{7}$ ( $O$ Amigo do Povo, Minerva Constitucional, O Publícola, el Censor Lusitano, todos ellos aparecidos en formato octavo), sobresale $O$ Correio Interceptado (1825-1826), de José Ferreira Borges. Impreso en Londres, forma parte de la llamada "imprensa da emigração londrina". Su redactor, importante líder del liberalismo portugués, estaba exiliado en Inglaterra debido a la avanzada de las fuerzas absolutistas en su país que, en 1823, habían logrado poner fin al primer gobierno liberal. ${ }^{8}$ Destacamos este periódico porque es uno de los pocos que explicita los motivos de la elección de un formato menor, específicamente del tamaño dozavo (la hoja medía $8 \mathrm{~cm}$ de ancho por 13 $\mathrm{cm}$ de alto). Esta información, unida a otros testimonios de la época, permite construir hipótesis que arrojan un poco de luz acerca del tipo de apropiación que se hacía -o que se esperaba que se hiciera- de los periódicos de tamaño pequeño. Pero, antes de adentrarnos en las publicaciones

\footnotetext{
${ }^{6}$ Citamos los periódicos indicando entre paréntesis el número dentro de la serie y luego la paginación original si la tiene. En las citas, respetamos en todos los casos la ortografía y los signos gráficos de las fuentes originales (puntuación, cursivas, negritas, mayúsculas).

${ }^{7}$ El 24 de agosto de 1820, en la ciudad de Porto, tuvo lugar un pronunciamiento militar que resultó en la llamada Revolução de 1820. Este movimiento, de carácter liberal, si bien cuestionó la estructura del Estado portugués del Antiguo Régimen, declaró fidelidad al rey d. João VI, quien por entonces se encontraba en Río de Janeiro, donde se había trasladado tras las invasiones napoleónicas. En septiembre de 1820, la Junta de Gobierno de Porto se unió a la de Lisboa conformando un gobierno unitario para todo el reino. Se convocaron las cortes constituyentes, con la misión principal de elaborar una constitución. La carta constitucional fue jurada por el rey en febrero de 1821. Tras el regreso de João VI a Portugal, en julio de ese año, el país devino una monarquía constitucional. Sobre este tema, así como sobre la reacción contrarrevolucionaria al movimiento vintista, véanse los artículos de Nobre Vargues y de Reis Torgal que integran el volumen 5, titulado O Liberalismo (2014), de la História de Portugal dirigida por José Mattoso. Acerca de las reformas políticas llevadas adelante durante el trienio liberal, puede consultarse el artículo de Tavares de Almeida, Branco y Silveira Sousa (2016) citado en la bibliografía.

${ }^{8}$ En mayo de 1823, el infante d. Miguel (hijo de d. João VI y de la reina d. Carlota Joaquina) encabezó una sublevación en Vila Franca contra el gobierno liberal, de ahí que, en la historiografía portuguesa, se conozca este episodio como Vilafrancada. Las consecuencias del levantamiento fueron la disolución del gobierno, la suspensión de las cortes, el exilio de los más importantes líderes liberales y la consolidación del movimiento absolutista antiliberal, que culminará, en 1828, con el nombramiento de d. Miguel como rey absoluto de Portugal. Para esta cuestión específica, además de consultar la História de Portugal de Mattoso, son útiles los trabajos de la historiadora portuguesa Maria Alexandra Lousada, como "El miguelismo o la contrarrevolución en Portugal" (1996) y "Portugal em guerra: a reacção anti-liberal miguelista do século XIX" (2014). Por otra parte, el ensayo de Reis Torgal A contra-revolução durante o período vintista, de 1978, presenta un apartado específico sobre el periodismo contrarrevolucionario.
}

Rev. Bras. Lit. Comp. Niterói, v. 22, n. 39, pp. 121-132, jan. /abr. 2020.

https://doi.org/10.1590/2596-304X20202239mlr 
específicas, haremos un repaso breve por los usos principales a los que se destinaron los formatos menores en la historia del impreso.

\section{Una fórmula editorial de dos caras}

Popkin enfatiza que los periódicos franceses de la época de la Revolución, a diferencia de los ingleses, seguían pareciéndose al libro. Las nuevas tecnologías mediáticas, para legitimarse, suelen tomar prestados rasgos de las tecnologías que las precedieron inmediatamente (Bolter y Grusin, 2000, p. 260). Siguiendo este razonamiento, podría pensarse que la prensa, por lo menos aquella que circuló bajo lo que Roger Chartier llama el "antiguo régimen tipográfico" (Chartier, 1994, p. 27), heredó del orden libresco la correspondencia entre el tamaño del impreso, su contenido, el público al que se dirigía y el uso al que se lo destinaba. ¿Qué determinaciones se articulaban en torno a la dimensión física de un libro? Martyn Lyons recoge la clasificación de los formatos renacentistas propuesta por Armando Petrucci, en la que se aclara esta cuestión:

[El primer tipo de libro] es el libro da banco, que se leía en un banco o una mesa. Se trataba de un libro de tamaño grande, de estudio y posiblemente destinado al uso universitario. [...]. El segundo tipo de libro es el libro humanista, que tenía un formato grande, en folio, o un formato en cuarto, más pequeño. A diferencia del primero, el libro humanista no estaba diseñado para ser usado en iglesias o universidades ni tenía finalidad de estudio, sino que estaba dirigido a hombres laicos y adinerados y a sus esposas. [...]. La tercera categoría dentro de la clasificación de Petrucci, y la más popular, corresponde al libro de bisaccia o libro de alforja, que tenía un formato pequeño y era fácil de transportar, tal como su nombre lo indica, en la alforja de un mercader, un fraile predicador, un peregrino o un artesano. (Lyons, 2012, p. 138).

El formato en octavo se asociaba con este último tipo libresco, cuya cualidad definitoria -el hecho de ser transportable y guardable en un continente pequeño- lo asemeja a nuestros libros de bolsillo. ${ }^{9}$ Hay un término en inglés que es bien gráfico al respecto: "pocket companion", una invención que, en el rubro tipográfico, resulta de la voluntad de conectar el libro con el cuerpo y sus desplazamientos. Por ello, los pequeños formatos se usaron mucho para los libros piadosos, objetos que debían estar en permanente contacto con el sujeto ya que la práctica devocional que habilitaban funcionaba como hilo conductor del día. Para las clases pudientes, existieron libros de horas de tamaño minúsculo, adornados como auténticas joyas y que se llevaban colgados al cuello como signo del estatus del portador (López Montilla, 2012, p.57). Pero también tuvieron sus versiones más humildes, elaboradas a partir de materiales de baja calidad y tipos fatigados. Chartier señala que durante el siglo XVIII era común que los campesinos tuviesen las Horas contantemente "en su bolsillo en el trabajo, y en las manos en el momento del descanso" (Chartier, 1994, p.185). La imagen, extraída de un apólogo de los Amigos de la Constitución de Auch, es iluminadora en su fragmentariedad al enfatizar los espacios donde el objeto impreso se colocaba alternativamente. Las manos del campesino sobre las que se asienta el libro abierto son el revés exterior del pliegue minúsculo en el que se lo

\footnotetext{
${ }^{9}$ Dado que el término "de bolsillo" se generalizó alrededor de mitad del siglo XIX, preferimos referirnos a los tamaños de los impresos usando las denominaciones de formato. Sobre este asunto, véase "El bolsillo: del enquiridión a las colecciones del siglo XIX", de Fermín de los Reyes Gómez (2018), donde el autor hace una relación de los términos que históricamente se usaron para denominar los libros en pequeño formato: enquiridión o manual, faltriquera y portátil.
}

Rev. Bras. Lit. Comp. Niterói, v. 22, n. 39, pp. 121-132, jan. /abr. 2020.

https://doi.org/10.1590/2596-304X20202239mlr 
guarda durante la labor, así como las horas de trabajo son el revés secular -un exterior mundano- del tiempo sagrado de la recitación de las oraciones a Dios.

Mientras en la época del manuscrito los pequeños impresos se destinaban exclusivamente a los materiales de rezo, en la era de Gutenberg, los fabricantes de libros extendieron el empleo de los formatos pequeños más allá del ámbito de la devoción. Encontraron en los tamaños reducidos muchas ventajas, entre las que destacaba la portabilidad y el costo más económico debido al menor uso de papel. Fue Aldo Manuccio quien, a fines del siglo XV, lanzó por primera vez una colección de libros de autores clásicos en formato octavo. Durante la centuria siguiente, la moda de los volúmenes pequeños se expandió por toda Europa de la mano de los humanistas $\mathrm{y}$, al despuntar el siglo XVIII, las ediciones de envergadura reducida ya representaban la mayor parte de la producción impresa. El formato folio quedó reservado, entonces, casi exclusivamente para obras de gran volumen, como diccionarios y enciclopedias. Sin embargo, en el transcurso del Siglo de las Luces, incluso la predilección de los grandes tamaños para ese tipo de materiales comenzó a cuestionarse. La portabilidad constituía un rasgo de los impresos a tener en cuenta si se quería garantizar un uso y circulación adecuados. Los filósofos ilustrados, imbuidos en su afán de extender los nuevos saberes, admiraron de la Iglesia su idoneidad para crear lo que hoy llamaríamos "fórmulas editoriales" exitosas, en las cuales las dimensiones físicas no eran una característica menor. Así, Voltaire le reprochaba sarcásticamente a Jean le Rond D'Alembert haber publicado la Encyclopédie en un formato grande: "Nunca veinte volúmenes in-folio provocarán la revolución; son los pequeños libros portátiles a treinta sueldos los que deben temerse. Si el Evangelio hubiese costado mil doscientos sestercios, la religión cristiana nunca se hubiese impuesto" 10 . Las quejas de Voltaire no cayeron en saco roto aunque por motivaciones pecuniarias más que filantrópicas. De ello es testimonio la guerra comercial que se desató en torno a la segunda edición de la Encyclopédie: la casa tipográfica responsable del proyecto de la edición in-quarto, en el que estaba involucrado Charles-Joseph Panckoucke, quiso a toda costa impedir la publicación de otra edición en octavo, que salía menos de la mitad del valor de la primera y con la cual resultaba difícil competir (Darton, 1982, p. 168-177).

Pero más allá de las cuestiones económicas y comerciales, la imaginación de los lectores dieciochescos fue cautivada por los libros pequeños atendiendo al deseo de vencer los obstáculos que el poder interponía a la libre circulación de las ideas. Muy sugerentemente, el escritor francés Louis-Sébastian Mercier escribía en 1782:

Estos libritos tienen la ventaja de que podemos guardarlos en el bolsillo, de que podemos hacer uso de ellos en los momentos de descanso, durante los paseos, y servirnos de ellos durante los viajes. ¿No podríamos eludir la inquisición literaria, tan ardiente y tan inquieta, que se opone a la introducción de los más estimados libros filosóficos, al reducirlos a los pequeños formatos ${ }^{11}$

Esto, que podía pensarse en relación con los libros, también era válido para otra clase de impresos, como el periódico. De hecho, la posibilidad de sustraerse al control de la censura constituye la motivación principal que el portugués Ferreira Borges atribuyó a la elección del tamaño pequeño para su publicación $O$ Correio Interceptado. En las palabras iniciales dedicadas al lector, el escritor liberal afirmaba haber elegido ese formato para que su periódico:

[...] tornasse mais facilmente impresso para donde veio manuscrito, e escapasse por entre os dedos dos Senhores da Policia, e podesse enroladinho mirrar-se por espelho de

\footnotetext{
${ }^{10}$ Citado en la edición crítica del Dictionnaire philosophique dirigida por Christiane Mervaud (1994-1995, p. 14).

${ }^{11}$ Tomamos la cita de Midori Deaecto, 2011, p. 95. 
fechadura segundo fosse necessário, e passar por Breve da Marca se fosse deparar a mão de Beata. $(1,4)$

El contexto de cruda represión que siguió a la Vilafrancada y el restablecimiento de la censura previa ameritaban ese cuidado. Advertida de que los liberales exiliados intentarían hacer entrar clandestinamente sus publicaciones al reino, la policía de d. Miguel puso especial cuidado en ellas, sobre todo en las hojas provenientes de Londres. De hecho, eran previstas severas penas para aquellos que fuesen descubiertos leyendo o distribuyendo publicaciones prohibidas (Tengarrinha, 1993, p. 55-6). Si bien no podemos afirmar que los formatos menores hayan efectivamente funcionado para burlar el control policial, lo cierto es que Ferreira Borges insistió en la edición en dozavo, tamaño que eligió por segunda vez para publicar el otro periódico que sacó en Londres pocos años después: $O$ Palinuro (1830).

En relación con el formato del papel portugués, resultan interesantes las imágenes que el redactor empleó para referirse a él puesto que sugieren la existencia de una estrategia material ligada al proceso de difusión y recepción del periódico. Se trata de figuraciones que exageran la pequeñez de la publicación asociando esta cualidad material con su naturaleza clandestina. Así como la escritura microscópica era usada por los agentes secretos con el fin de sustraer la información a los ojos del enemigo, el objeto impreso creado por Ferreira Borges se representa, desde una dimensión táctil, en el límite de la manipulación: las manos de las autoridades -no ya los ojos- resultaban inservibles para manejar algo tan diminuto. Además, su pequeñez y levedad hacían posible guardarlo en una cajita bajo llave y/o propiciaban ciertos equívocos como confundírselo con un Breve da Marca, minúsculo librito impreso con oraciones que se llevaba debajo de la ropa para proteger a su portador del diablo, de enfermedades y de toda clase de catástrofes (terremotos, tempestades, rayos) ${ }^{12}$.

Esta representación estilizada y fantaseada de la forma del periódico está en perfecta sintonía con sus imaginarias condiciones de producción: según se cuenta en el texto inicial, el papel está enteramente conformado por cartas interceptadas por un oficial del correo. Son en total 63 epístolas, cada una de las cuales está firmada por un corresponsal distinto y ocupa un número completo. En ellas, Ferreira Borges "produz um discurso que não deixa pedra sobre pedra no edifício do Antigo Regime" (Santos Alves, 2017, p.13) criticando el aparato judicial anquilosado, el manejo discrecional del dinero público, la sacralización de la figura del Rey, el Portugal milagrero y supersticioso, la inercia de las costumbres de los antepasados. Dado el contexto de censura y persecución que fue consolidándose tras la Vilafrancada, solo restaba la esfera de la intimidad para construir un discurso de disenso semejante. En O Correio Interceptado, la práctica de interceptar la correspondencia, habitual en regímenes totalitarios que avanzan sobre la vida privada de los individuos, es usada en un sentido contrario, esto es, para burlar la prohibición dando a la publicidad aquello que sólo podía decirse en el marco de una sociabilidad íntima. Así, la ficción de escritura en la que se monta el periódico de Ferreira

\footnotetext{
${ }^{12}$ El Diccionario da Lingua Portugueza de António de Moraes Silva (1831) define "Breve da Marca" como "papel com certas orações, que serve de capa a relíquias, ou a flores bentas". Para conocer cómo se usaban estos objetos, son interesantes los datos que aporta Rui Tavares (2003) acerca de una discusión que tuvo lugar sobre ellos en la Real Mesa Censória en 1770. Gracias al informe del censor que quiso prohibirlos por considerarlos libritos supersticiosos, pueden conocerse varias de sus características: su denominación "da Marca" derivaba de que desde tiempo inmemorial se los confeccionaba en conventos de Marca de Ancona, provincia de los Estados Eclesiásticos; en ellos se imprimían las palabras de los Exorcismos, el principio del Evangelio de San Juan y el Responsorio con la oración de San Antonio; además de las oraciones, llevaban un papelito con algún agregado, como polvo de cementerios donde se creía estaban sepultados mártires; por último, se les atribuía admirables efectos benéficos. Por otro lado, Tavares incluye en su trabajo la foto de un impreso de similares características físicas a un Breve da Marca: Santíssimas e Armas da Igreja contra os Rayos, Tempestades e Trovões (Lisboa, 1760), libro que tan solo medía $4 \times 2 \mathrm{~cm}$ y que se llevaba colgado al cuello adentro de una bolsita.
} 
Borges y su formato pequeño constituyen de por sí, más allá del contenido de las epístolas, una forma de denuncia que patentiza la reducción de los espacios de libertad.

\section{Papeles públicos, formas privadas}

En On Longing, Susan Stewart (1992) analiza la miniatura y lo gigante como formas de representación desproporcionadas de la realidad. Concibe el tamaño pequeño como una exageración del interior y lo vincula con lo cerrado, lo doméstico y la cultura, en oposición a lo gigante, que enlaza con lo infinito, la exterioridad, lo público y lo natural. En la lectura de Stewart, lo pequeño aparece, entonces, desligado de lo público. Sin embargo, en $O$ Correio Interceptado, la imaginación sobre los impresos de reducidas dimensiones hace pensar más bien en un solapamiento de esferas: en el papel de Ferreira Borges, la mecánica de la publicidad funcionaba de tal manera que, de cierta forma, ocultaba los escritos íntimos en el sentido de que escondía las epístolas al darlas a la luz bajo condiciones materiales especiales.

Con $O$ Mestre Barbeiro las cosas resultan ligeramente diferentes. Dado que circuló en Porto Alegre en una época de relativa libertad de prensa ${ }^{13}$, el régimen de su palabra no era privilegiadamente el del murmullo. Por el contrario, su eficacia se medía por el grado de circulación y revuelo público que lograra suscitar. Sin embargo, esta modalidad de intervención tenía sus limitaciones, con las que puede vincularse, justamente, el tamaño del papel. La elección del formato menor revelaría, entonces, la conciencia que tenía su redactor de esas restricciones o, en otras palabras, su claridad acerca de los riesgos que corría su publicación. Hay que recordar que $O$ Mestre Barbeiro era un periódico satírico, que se nutría de las más variadas invectivas fundadas en aspectos personales de los individuos, por lo que en él se descorría en parte el velo que protegía la vida privada. Es decir, ensayaba mostrar lo que no había que mostrar, lo que redundaba en una escritura de predilección por las formas oblicuas, como la práctica del secreto en torno a la identidad del autor, el empleo de la ironía o el uso de motes cifrados - la mayoría injuriantes- para referir al enemigo político. ¿El formato menor de $O$ Mestre Barbeiro no podría ser también una forma más de oblicuidad que facilitaba decir aquello que no correspondía ocultándose tras las letritas que cabían en las reducidas dimensiones de las hojas de papel? Puesto que en ningún momento el papel de Silva Monteiro hace alusión a su tamaño -como sí lo hace el de Ferreira Borges- todo lo dicho acerca de él es materia especulativa que adquiere consistencia si se arman series con objetos contemporáneos de características semejantes. Ligar el periódico portoalegrense con la prensa francesa revolucionaria en los términos en los que la analiza Popkin, tal como lo propusimos al comienzo, supone un camino interpretativo, pero la asociación con el periódico portugués agrega una capa de sentido que incluye la dimensión de la manipulación del objeto impreso por parte de los lectores.

Retomando la cuestión de las formas oblicuas, habría que hacer notar que el papel brasileño se resguardaba a sí mismo a través de un tipo de materialidad asociada con los impresos destinados al consumo privado; en efecto, históricamente, los formatos menores se correlacionaron con la lectura individual, en silencio y en soledad (Melot, 2012, p. 191). Desde

\footnotetext{
${ }^{13}$ El Código Criminal del Imperio do Brasil, sancionado en 1830, velaba por el derecho de los ciudadanos a la libre expresión a la vez que establecía los abusos de imprenta y prescribía las penas -pecuniarias o de prisión-que cabían en cada caso. Asimismo, establecía un sistema de responsabilidades escalonado: el primer responsable penal era el impresor y sucesivamente el editor, el redactor y el vendedor. Esta era la ley que regía en 1835 . Como prueba de las oscilaciones en la libertad de prensa a la que dicha norma daba lugar, está el caso del impresor de $O$ Mestre Barbeiro, el francés Claude Dubreuil, que fue condenado en múltiples ocasiones a abandonar la provincia debido al desorden público que, según las autoridades, concitaban sus publicaciones. Las expulsiones se sucedieron en 1835, 1838, 1841 y 1850 (Barreto, 1986, p. 22-23).
}

Rev. Bras. Lit. Comp. Niterói, v. 22, n. 39, pp. 121-132, jan. /abr. 2020. 
esta perspectiva, se trataba de un tamaño sigiloso - si cabe el adjetivo- que atenuaba los riesgos que implicaba la circulación del papel para prevenir su eventual sustracción del espacio público. En una época muy conflictiva política y militarmente, con una ley de imprenta que tipificaba los abusos y establecía las correspondientes penas, un tipo de periódico como el que redactaba Silva Monteiro oscilaba por fuerza en el límite entre lo lícito y lo clandestino. En cualquier momento, debido a un artículo que excediera los límites tolerables de la injuria, podía caer sobre él la orden de prohibición. El formato menor era ideal, entonces, para ocultarlo en los pliegues de la ropa, llevarlo disimuladamente cerca del cuerpo con el objeto de salvar, paradójicamente, al propio cuerpo de las represalias de los enemigos o de la pena reservada para aquellos que portaban impresos ilícitos.

La íntima contigüidad entre el impreso y el cuerpo que posibilitan los formatos pequeños recuerda la idea de Stewart acerca de las piezas tipográficas miniatura: su posibilidad de oficiar como "talismán para el cuerpo y emblema del yo" (1992, p. 41). De hecho, como señalamos en relación con los Breves da Marca, la finalidad de los libros minúsculos no era solo la lectura, sino también la protección, en especial contra la muerte (Reyes Gómez, 2018, p.113). Esta caracterización, puesta a funcionar en publicaciones clandestinas o que rozaban lo prohibido, implica sentidos diversos. En principio, tanto en el periódico brasileño como en el portugués, la cuestión del ocultamiento en el cuerpo remite a la búsqueda imposible de un lugar de extrema reserva donde el objeto sea cuidado sin pausa y, con él, el cuerpo que lo cobija. Pero en $O$ Correio Interceptado, la idea adquiere otro vuelo. Aparecido en plena expansión del romanticismo portugués -con sus principales exponentes exiliados desde 1823-, el periódico de Ferreira Borges podría pensarse como una reafirmación romántica del yo ante el poder omnímodo que se imponía por sobre la libertad del individuo; en este sentido, el pequeño papel, de manera semejante a un amuleto o talismán, resguardaba al sujeto al constituir él mismo un reaseguro material, pretendidamente inviolable, para el libre ejercicio del pensamiento.

\section{Coda: periódicos fuera de serie}

Aunque solo sea en líneas generales, el primer factor que debe tenerse en cuenta a la hora de adjudicar formato a una obra es el contenido que va a albergar. Si no existen razones de peso, a primera vista parecería inexplicable imprimir un mapa muy detallado en formato dieciseisavo, o un libro escolar en folio prolongado o en plano. En ambos casos pueden darse excepciones, pero en principio no responderían al uso que de tales obras se hace normalmente. (Martínez de Sousa, "Formato", p. 401)

Aquello que a un diccionario como el de José Martínez de Sousa, abocado a dar cuenta de regularidades, no le interesa de manera prioritaria, constituyó el principal objeto de análisis de este artículo. Con certeza hay algo de excepcional en los periódicos analizados. Si bien, como parte del trabajo de historización de las publicaciones, propusimos series de impresos para evitar el riesgo de las lecturas anacrónicas, ese proceder metodológico no soslaya la singularidad de las hojas periódicas, que, por otra parte, se revela en el marco de coyunturas históricas muy precisas. $O$ Mestre Barbeiro fue el periódico más pequeño de los aparecidos en Porto Alegre durante los años de la Revolução Farroupilha. Este hecho, de por sí, constituye una "excepcionalidad". Pero, además, se pueden señalar otras. Si volvemos a la cita de Barreto que copiamos al comienzo del trabajo, el historiador gaúcho parece sugerir que existía cierta asimetría entre la notable potencia beligerante del papel de Silva Monteiro y su tamaño menor. Se trata de una asimetría similar a la que Michel Melot plantea, en la cita del epígrafe, como fundamento de la fascinación que despiertan los libros pequeños. Stewart también aborda esa cuestión, en su caso en relación con las micrografías. Acerca de las letritas de las escrituras 
ultra pequeñas, dice: "Casi invisible, la marca continúa significando; su significación se acrecienta en vez de disminuir por su pequeñez" (Stewart, 1992, 38). ¿Esa desproporción entre contenido y continente no constituye una característica intrínseca de los formatos menores o, por lo menos, un rasgo que queda evidenciado en algunos de sus usos? Visto esto en $O$ Mestre Barbeiro, el desacomodo entre su tamaño y lo estentóreo de su estilo se torna palpable; sin embargo, como indica Barreto, las injurias impresas en sus páginas no perdían la potencia ultrajante. ¿La acrecentaban? Tal vez la pequeñez le otorgase al papel un plus de vigor porque facilitaba su circulación a fuerza de escabullirse entre las manos y los bolsillos de los lectores.

Para el caso de $O$ Correio Interceptado, enfatizamos la propia representación del periódico que propone el redactor analizando las comparaciones utilizadas para referirse al formato. Consideramos que ellas iluminan los sentidos y usos asociados con los impresos de tamaño menor. El hecho de que pudiese guardarse "enroladinho" en un continente pequeño bajo llave -cofrecito, caja, cajón- acentuaba la dimensión tridimensional del impreso en tanto objeto manipulable. Siguiendo estas figuraciones, el papel se confundía con el lugar donde podía guardárselo porque constituía él mismo un interior insondable habida cuenta de que en él se "guardaban" pensamientos, que -no está de más recordarlo- se debían ocultar a la luz del día porque revelaban la verdad del parecer de un sujeto. Por otra parte, Ferreira Borges filiaba su papel con un librito devocional -claro que como un modo de subterfugio-, lo que en cierto sentido implicaba reconocer la eficacia de las estrategias eclesiásticas de difusión de los textos religiosos. Como ya señalamos, los Breves da Marca, tipos de impresos con los que $O$ Correio Interceptado podía confundirse, eran minúsculos objetos devocionales que se llevaban pegados al cuerpo y que tenían, paradójicamente, la capacidad de luchar contra las fuerzas malignas más poderosas. ¿No era eso lo que el escritor liberal aspiraba para su pequeña hoja? Dejar en lo pequeño el trazo de lo grande que, en su caso, no era otra cosa que la libertad de pensar.

\section{REFERENCIAS}

BARRETO, Abeillard. Primórdios da Imprensa no Rio Grande do Sul. Porto Alegre: Comissão Executiva do Sesquicentenário da Revolução Farroupilha. Subcomissão de Publicações e Concursos, 1986.

FERREIRA BORGES, José. O Correio Interceptado. Londres: Imprensa de M. Calero, 18251826.

BOLTER, Jay and GRUSIN, Richard. Remediation: Understanding New Media. Cambridge: MIT Press, 2000.

CHARTIER, Roger. Libros, lecturas y lectores en la edad moderna. Madrid: Alianza, 1994.

DARTON, Robert. L'aventure de l’Encyclopédie. 1775-1800. Un best-seller au siècle des Lumières. París: Librairie Academique Perrin, 1982.

FEBVRE, Lucien and MARTIN, Henri-Jean [1958]. O aparecimento do livro. Lisboa: Fundação Calouste Gulbenkian, 2000.

FLORES, Moacyr. Revolução Farroupilha. Porto Alegre: Martins Livreiro-Editor, 1985.

GASKELL, Philip [1972]. Nueva introducción a la bibliografía material. Gijón: Trea, S.L., 1999.

KÜHN, Fábio. Breve história do Rio Grande do Sul. Porto Alegre: Leitura XXI, 2002.

LÓPEZ MONTILLA, María Jesús. El libro de horas. Un libro selecto de devoción privada. Madrid: La Ergástula, 2012.

LOUSADA, Maria Alexandra. “El miguelismo o la contrarrevolución en Portugal”. In: PAYNE, Stanley, coord. Identidad y nacionalismo en la España contemporánea: el carlismo, 1833-1975. Madrid: Actas, 1996, s/p.

Rev. Bras. Lit. Comp. Niterói, v. 22, n. 39, pp. 121-132, jan. /abr. 2020. 
"Portugal em guerra: a reacção anti-liberal miguelista do século XIX". In: MARCHI, Riccardo, coord. As raízes profundas não gelam? Ideias e percursos das direitas portuguesas. Lisboa: Texto, 2014, p. 81-112.

LYONS, Martin. Historia de la lectura y la escritura en el mundo occidental. Buenos Aires: Ampersand, 2012.

MARTÍNEZ DE SOUSA, José. Diccionario de bibliología y ciencias afines. Madrid: Fundación Germán Sánchez Ruipérez, 1993.

MELOT, Michel. Livro. San Pablo: Ateliê Editorial, 2012.

MIDORI DEAECTO, Marisa. O império dos livros. Instituições e práticas de leitura na São Paulo oitocentista. San Pablo: Edusp, 2011.

MERVAUD, Christiane (dir.). Dictionnaire philosophique. OEuvres complètes de Voltaire, tomos 35 y 36. Oxford: Voltaire Foundation, 1994-1995.

MORAES SILVA, Antonio de. Diccionario da Lingua Portugueza. Lisboa: Impressão Régia, 1831.

NEVES ALVES, Francisco das. Revolução Farroupilha: estudos históricos. Río Grande: Fundação Universidade Federal do Rio Grande, 2004.

NOBRE VARGUES, Isabel. "O processo de formação do primeiro movimento liberal: a Revolução de 1820". In: REIS TORGAL, Luís and ROQUE, João Lourenço, coord. $O$ Liberalismo, vol. 5 de la História de Portugal (dir. Jorge Mattosso). Lisboa: Círculo de Leitores e Autores, 2014.

e REIS TORGAL, Luís. "Da revolução a contra- revolução: vintismo, cartismo, absolutismo. O exílio político". In: REIS TORGAL, Luís and ROQUE, João Lourenço, coord. O Liberalismo, vol. 5 de la História de Portugal (dir. Jorge Mattosso). Lisboa: Círculo de Leitores e Autores, 2014.

PESAVENTO, Sandra. A Revolução Farroupilha. San Pablo: Brasiliense, 1985.

PETRUCCI, Armando, ed. Libri, scrittura e pubblico nel Renascimento. Guida storica e critica. Roma: Laterza, 1979.

POPKIN, Jeremy. "Journals: the New Face of the News". In: DARTON, Robert and ROCHE, Daniel, orgs. Revolution in Print. The Press in France 1775-1800. Los Ángeles: University of California Press, 1989.

and CENSER, Jack. "Some paradoxes of the eighteenth-century periodical". In: LÜSEBRINK, Hans-Jürgen and POPKIN, Jeremy. Enlightment, Revolution and the Periodical Press. Oxford: Voltaire Foundation, 2004.

RECOPILADOR Liberal (O). Porto Alegre: Typ. De V. F. de Andrade, 1835.

SILVA MONTEIRO, António José da. O Mestre Barbeiro. Porto Alegre: Typ. De C. Dubreuil \& Comp., 1835.

SÁNCHEZ VIGIL, Juan Miguel, coord. La cultura en el bolsillo. Historia del libro de bolsillo en España. Madrid: Trea, 2018.

SANTOS ALVES, José Augusto dos. "O espaço da escrita epistolar com um novo significado. O Correio Interceptado (1825-1826)". Cultura. Revista de História e Teoria das Ideias, v. 36, 2017, p 1-16, https://journals.openedition.org/cultura/3740

STEWART, Susan. On Longing. Narratives of Miniature, the Gigantic, the Souvenir, the Collection. Durham y Londres: Duke University Press, 1992.

STOLZE LIMA, Ivana. "Pasquins e cidadania no período regencial". In: LUSTOSA, Isabel, dir. Imprensa, história e literatura. Río de Janeiro: Edições Casa de Rui Barbosa, 2008.

TAVARES DE ALMEIDA, Pedro; BRANCO, Rui; SILVEIRA E SOUSA, Paulo. "El Estado en el Portugal decimonónico: el liberalismo entre el sueño y la razón”. Historia y Política, no. 36, 2016, p. 129-160, https://recyt.fecyt.es/index.php/Hyp/article/view/35767

Rev. Bras. Lit. Comp. Niterói, v. 22, n. 39, pp. 121-132, jan. /abr. 2020. 
TAVARES, Rui. "Uma teologia da recepção? Os censores (em desacordo) contra a superstição, Portugal 1770-1771”. Lusitania Sacra, tomo XV, 2003, pp. 211-238, https://repositorio.ucp.pt/handle/10400.14/4410

TENGARRINHA, José. História da imprensa portuguesa. Lisboa: Caminho, 1989.

- Da liberdade mitificada à liberdade subvertida. Uma exploração no interior da repressão à imprensa periódica de 1820 a 1828. Lisboa: Colibrí, 1993.

Maria Laura Romano é Doutora (Instituto de Literatura Hispanoamericana da Universidad de Buenos Aires, Argentina) e bolsista pós-doutoral do Conicet. É professora de Teoría y Análisis Literario no Traductorado en Portugués del Instituto Superior en Lenguas Vivas Juan Ramón Fernández, e atua em oficinas de leitura e escrita na Universidade Nacional de General Sarmiento. Escreveu tese sobre "Monstruos de la razón. Periódicos no ilustrados en la región platina (1820-1830)".

Submetido em 12/11/2019

Aceito em 20/12/2019 